\title{
Glenohumeral Microfracturing of Contained Glenohumeral Defects: Mid- to Long-term Outcome
}

\author{
Julia K. Frank, M.D., Philipp R. Heuberer, M.D., Brenda Laky, Ph.D., Werner Anderl, M.D., \\ and Leo Pauzenberger, M.D., Ph.D.
}

\begin{abstract}
Purpose: To report mid- to long-term clinical and radiological outcomes after microfracturing for symptomatic chondral defects of the glenohumeral joint Methods: All patients who underwent glenohumeral arthroscopic microfracturing between 2002 and 2012 at a single center were considered for inclusion in this retrospective study. Clinical outcome was evaluated using the Constant Score, Oxford Shoulder Score, and Subjective Shoulder Value. Progression of joint space narrowing, sclerosis, marginal osteophytes, and presence of cysts over time were assessed using 4 different radiological grading systems Results: A total of 16 patients $(n=9$ female, $n=7$ male) with a mean age of $51.8 \pm 12.6$ years at the time of surgery and a mean follow-up of $122 \pm 51.2$ months (range, 61-204 months) were included in this retrospective study. Nine patients $(56.3 \%)$ showed an isolated chondral defect, while 7 patients $(43.8 \%)$ had concomitant pathologies. Constant Score $(60.3 \pm 12.7$ vs. $85.9 \pm 9.3 ; P<.001)$, Oxford Shoulder Score $(29.0 \pm 5.8$ vs. $42.4 \pm 4.5 ; P<.001)$, and Subjective Shoulder Value $(23.9 \pm 7.4$ vs. $84.3 \pm 10.9 ; P<.001)$ changed significantly from pre- to postoperative. The majority of patients $(88 \%)$ were able to return to their preoperative level of activity. Three patients (19.8\%) developed radiological signs of progressive glenohumeral degeneration during the study period. However, only 1 patient (6.25\%) showed a progression of arthritic changes of more than 1 grade according to radiographic classifications. Two patients $(12.5 \%)$ underwent revision surgery to a hemi shoulder arthroplasty during the study period at 12 and 36 months after the initial procedure Conclusions: Glenohumeral microfracturing is commonly performed together with other procedures, but seems to be a feasible treatment option for contained cartilage lesions in active patients reproducibly yielding good mid- to long-term outcome. Level of Evidence: Level IV, therapeutic case series.
\end{abstract}

C ontained articular cartilage lesions of the shoulder have various causes including degenerative processes, acute injury, infection, rotator cuff tear arthropathy, and chronic repetitive overload. ${ }^{1-3}$ These lesions often fail to heal spontaneously because of their avascularity and minimal chondrocyte migration and propagation. ${ }^{4}$ They are associated with pain, loss of function and can eventually progress to osteoarthritis. ${ }^{5,6}$ Whereas total shoulder arthroplasty of diffuse articular cartilage loss in the glenohumeral joints of older and less active patients is well established,

From the Vienna Shoulder $\theta$ Sports Clinic, Vienna, Austria (J.K.F. P.R.H., B.L., W.A., L.P.); Austrian Research Group for Regenerative and Orthopedic Medicine (AURROM), Vienna, Austria (P.R.H., B.L., W.A.); and Sports Surgery Clinic, Dublin, Ireland (L.P.).

All authors made substantive intellectual contributions to the study. The authors' responsibilities were as follows: L.P. and P.H. initiated the study regarding conception and design; J.K.F. collected the data; L.P., P.H., J.K.F., and B.L. performed data analysis and interpretation; W..A supervised the conduction of the study; all authors were actively involved in drafting the manuscript or revising it critically for important intellectual content and have given final approval of the version to be published. significant controversy remains in selecting and refining successful operative techniques to address symptomatic glenohumeral cartilage lesions in the shoulders of young, active patients. ${ }^{1,7}$ Considering treatment options for chondral defects, the surgeon must consider the size, depth, location, and chronicity of the lesion. In addition, the overall alignment of the joint must be evaluated. Focal cartilage lesions of the glenohumeral joint are often difficult to diagnose and require a refined, focused physical examination, and imaging studies. Standard radiographs of the shoulder are

The authors report that they have no conflicts of interest in the authorship and publication of this article. Full ICMJE author disclosure forms are available for this article online, as supplementary material.

Received October 21, 2019; accepted April 29, 2020.

Address correspondence to Leo Pauzenberger, M.D., Ph.D., Vienna Shoulder $\theta$ Sports Clinic, Hartmann 15/10, 1050 Vienna, Austria. E-mail: leopauzenberger@rcsi.com

(C) 2020 THE AUTHORS. Published by Elsevier Inc. on behalf of the Arthroscopy Association of North America. This is an open access article under the CC BY-NC-ND license (http://creativecommons.org/licenses/by-nc-nd/4.0/). 2666-061X/191239

https://doi.org/10.1016/j.asmr.2020.04.016 
sufficient to detect large osteochondral defects of the humeral head or glenoid, ${ }^{8}$ whereas computed tomography scans with 3-dimensional reconstruction detect even subtle osteochondral defects. However, magnetic resonance imaging (MRI) remains the gold standard in diagnosing focal chondral lesions, although sensitivity of standard MRI is affected by the limited cartilage thickness of the glenohumeral joint. . Magnetic resonance arthrography has been shown to be significantly more accurate, correctly identifying cartilage defects in more than $70 \%$ of patients as reported in a study with arthroscopic follow-up. ${ }^{10}$

Microfracturing is a technique to address focal chondral defects by perforating the subchondral bone to stimulate a bleeding response. ${ }^{11}$ Subsequently, this leads to release of mesenchymal stem cells forming a clot that fills the defect and results in repair of the defect with fibrocartilage. ${ }^{12,17-19}$ Since microfracturing was popularized by Steadman et al., ${ }^{11}$ it has been widely used as an effective therapeutic option for full-thickness cartilage defects of the knee. Because of the many advantages of microfracturing including technical simplicity, low patient morbidity, and cost effectiveness ${ }^{12}$ would also be a very interesting option for the treatment of glenohumeral chondral lesions. However, literature on microfracturing in the shoulder is scarce.

Thus, the purpose of this study was to report mid- to long-term clinical and radiological outcomes after microfracturing for symptomatic chondral defects of the glenohumeral joint. The hypothesis of the current study was that clinical outcome would be significantly improved from baseline at the latest follow-up.

\section{Methods}

All patients who underwent arthroscopic microfracturing between January 2002 and January 2012 at a single orthopaedic department were considered for inclusion in the present retrospective study. Patients with irreparable rotator cuff tears, rotator cuff arthropathy, avascular osteonecrosis, fractures, and systemic inflammatory diseases were excluded for the current study. Patients with contained chondral defects of the humeral head, glenoid, or both measuring less than $25 \mathrm{~mm}$ in diameter and with arthroscopically verified grade IV lesions according to the Outerbridge classification ${ }^{15}$ were considered appropriate for treatment with microfracturing. Microfracturing was often performed alongside additional procedures such as biceps tenodesis, subacromial decompression, bursectomy, and removal of calcium depots.

Shoulder surgeries were performed at the authors' institution by 4 fellowship-trained shoulder surgeons during the studied period. The surgical technique for glenohumeral microfracturing was equivalent to the technique described for the knee joint. ${ }^{11}$ Any loose cartilage was removed and the edges of the defect were debrided using an arthroscopic shaver or a curette to create a stable wall around the defect. Using a curette, the calcified cartilage was debrided, while keeping the subchondral bone intact. The subchondral bone layer was penetrated with a microfracture awl with holes approximately 3- to 5-mm apart. After removing remnant bone and debris, bleeding from the microfracturing holes was checked by reducing irrigation pressure.

Postoperatively, the rehabilitation program depended mainly on associated pathology and additional procedures carried out. Generally, in cases of reconstructive procedures (e.g. rotator cuff repair) the arm was immobilized in a sling for 4 to 6 weeks, while allowing passive and active-assisted exercises from early on; active exercises were allowed after 6 weeks. When no reconstructive procedures were performed, the arm was immobilized in a sling for 2 weeks, but the aim of early rehabilitation was to get the shoulder back to active movement as soon as possible.

In all cases when microfracturing was performed, load bearing and weight lifting was restricted for a minimum of 6 weeks.

Pre- and postoperative outcomes were evaluated using the Constant Score, Oxford Shoulder Score, and Subjective Shoulder Value. Radiological evaluation included 4 different radiographic grading systems according to Guyette et al., ${ }^{20}$ Weinstein et al., ${ }^{21}$ Kellgren and Lawrence, $^{22}$ and Samilson and Pietro ${ }^{23}$ to assess progression of joint space narrowing, sclerosis, marginal osteophytes, and presence of cysts over time. The radiographs consisted of an anteroposterior exposure with the shoulder in a $20^{\circ}$ internal, external rotation, Bernageau, and axillary radiograph. Data and patients were assessed by a single independent examiner not directly involved in the surgical procedures (J.K.F.). Pre- and postoperative radiographs were assessed regarding progression of signs for degenerative joint disease by 2 independent examiners not directly involved in the surgical procedures (J.F.K., L.P.).

The current study was approved by the internal review board of the St. Vincent Hospital Vienna (\#EK17/2018).

\section{Statistical Analysis}

Descriptive statistics were used to present patient characteristics. Data distribution was assessed by the Kolmogorov-Smirnov-test. Paired $t$-tests were performed to compare pre- and postoperative outcome. A comparison of outcomes according to the location of lesions was performed using l-way analysis of variance with Tukey post hoc test. Statistical significance was set at the conventional $P$ value of $<.05$ (2-sided). All data were analyzed using SPSS Statistics 23 (IBM Corporation, Armonk, NY).

\section{Results}

The hospital database search yielded a total of 18 cases potentially eligible for inclusion, of which 16 
Table 1. Comparisons Between Pre- and Postoperative Clinical Scores $(\mathrm{n}=14)$

\begin{tabular}{lccc}
\hline Clinical Scores & Preoperative & Postoperative & $P$ Value \\
\hline $\begin{array}{c}\text { Constant Score } \\
(0-100 \text { points })\end{array}$ & $60.3 \pm 12.7$ & $85.9 \pm 9.3$ & $<.001$ \\
$\begin{array}{c}\text { Oxford Shoulder Score } \\
\quad(60-12 \text { points })\end{array}$ & $29.0 \pm 5.8$ & $42.4 \pm 4.5$ & $<.001$ \\
$\begin{array}{c}\text { Subjective Shoulder } \\
\text { Value (\%) }\end{array}$ & $23.9 \pm 7.4$ & $84.3 \pm 10.9$ & $<.001$ \\
\hline
\end{tabular}

patients $(88.9 \%, \mathrm{n}=2$ patients not available for follow-up) with a mean follow-up of $122 \pm 51.2$ months (range, 61-204 months) could ultimately be included in the study. There were slightly more female $(56 \%)$ than male $(44 \%)$ patients with a mean age at time of surgery of $51.8 \pm 12.6$ years and mean body mass index $25.4 \pm 3.6$. Despite the 2 patients who needed further surgery after the initial procedure (revision to hemiarthroplasty), all patients in the final analysis exceeded the patient acceptable symptomatic state threshold of 44 points in the Constant Score.

Surgery was performed on the right shoulder and the dominant arm in $63 \%$ of all cases. Of the ${ }^{16}$ shoulders, microfracturing was performed on the humeral head in $8(50 \%)$ cases, on the glenoid surface in $4(25 \%)$ cases, and on both the humeral and glenoid cartilage in 4 $(25 \%)$ patients.

Nine patients $(56.3 \%)$ had an isolated chondral defect, which was treated with microfracturing and partial subacromial bursectomy as part of routine arthroscopic evaluation of the subacromial space.

Seven patients $(43.8 \%)$ showed concomitant pathologies alongside chondral defects, which were treated at the time of microfracturing with removal of an intratendinous calcium deposit $(\mathrm{n}=2)$, subacromial decompression $(\mathrm{n}=77)$, acromioclavicular joint resection $(n=2)$, biceps tenotomy or tenodesis $(n=4)$, supraspinatus tendon repair $(\mathrm{n}=5)$, arthroscopic labral repair $(\mathrm{n}=1)$, and superior labral anterior posterior repair $(n=1)$. The average diameter of the chondral lesions was documented as $19.7 \pm 4.9 \mathrm{~mm}$ (range, 10-25) overall, $20.8 \pm 2.9 \mathrm{~mm}$ (range, 15-25) humeral, and $16.3 \pm 3.7 \mathrm{~mm}$ (range, 10-20) on the glenoid. Two patients $(12.5 \%)$ underwent subsequent surgery at 12 and 36 months after the initial procedure for increasing pain and loss of function. In both cases, a hemiarthroplasty was performed as revision procedure.

All clinical outcome measures of the remaining patients $(\mathrm{n}=14)$ improved significantly from baseline to the latest follow-up $(P<.001$; Table 1; Fig 1). A comparison between isolated and bipolar lesions did not show significant differences in outcome between groups (Table 2$)$. The majority of patients $(87.5 \%)$ were able to return to their previous level of activity.

During the follow-up period, 3 patients $(25.0 \%)$ developed radiological signs of progressive glenohumeral degeneration. However, only 2 patients $(16.7 \%)$ showed a progression of degenerative changes of more than 1 grade according to the 4 radiographic grading systems (Table 3). There were no intra-, peri-, or postoperative complications directly related to the surgery reported in the study group.

\section{Discussion}

The results of the present study suggest that microfracturing is an effective treatment for contained, focal, chondral defects of the glenohumeral joint, providing significant clinical improvements and allowing return to full activity in the majority of patients from baseline to the mid- to long-term follow-up. However, because microfracture was often performed in conjunction with other procedures, its isolated clinical value as a standalone procedure is not yet fully clear.

Although indications for microfracturing as well as surgical techniques have been clearly defined for the knee joint, there is a paucity of literature that discusses glenohumeral microfracturing specifically in long-term studies for this procedure. From a biological point of view, there are significant differences between the shoulder joint and the knee joint because the articular cartilage thickness is significantly less.13 Specifically, the cartilage depth of the glenoid fossa and the humeral head averages $1.88 \mathrm{~mm}$ and $1.24 \mathrm{~mm}$, respectively. ${ }^{13,14}$ Diagnosis of symptomatic full thickness chondral lesions is difficult and nonspecific. Some studies suggest that arthroscopic management is more successful in

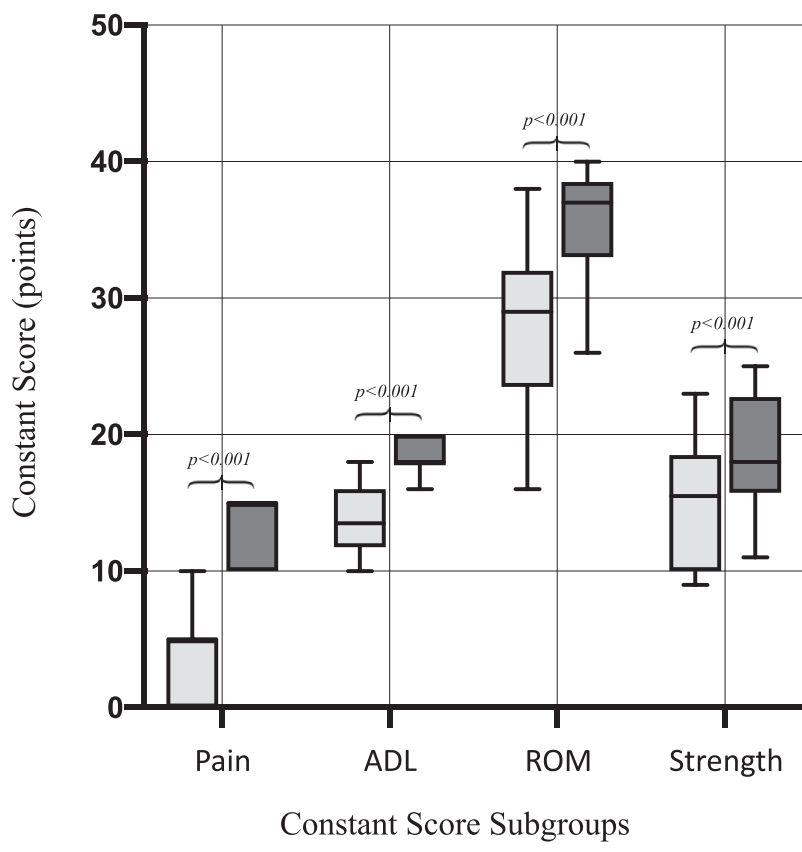

Fig 1. Constant score subgroups pain, activity of daily living (ADL), range of motion (ROM), and strength before (light gray) and at a mean $122 \pm 51.2$ months after (dark gray) microfracturing. 
Table 2. Comparisons Between Isolated and Bipolar Lesions Regarding Outcome $(\mathrm{n}=14)$

\begin{tabular}{|c|c|c|c|c|}
\hline & Humeral $(n=7)$ & Glenoidal $(\mathrm{n}=3)$ & Glenohumeral $(\mathrm{n}=4)$ & $P$ Value \\
\hline $\begin{array}{l}\text { Constant } \\
\text { Score }(0-100 \text { points })\end{array}$ & $88.4 \pm 9.3$ & $91.3 \pm 8.1$ & $77.3 \pm 4.1$ & .070 \\
\hline $\begin{array}{l}\text { Oxford Shoulder } \\
\text { Score (60-12 points) }\end{array}$ & $43.9 \pm 4.9$ & $44.7 \pm 2.3$ & $38.3 \pm 2.4$ & .078 \\
\hline $\begin{array}{l}\text { Subjective Shoulder } \\
\text { Value }(\%)\end{array}$ & $85.7 \pm 11.3$ & $93.3 \pm 5.8$ & $75.0 \pm 5.8$ & .065 \\
\hline
\end{tabular}

shoulders with an isolated humeral defect. ${ }^{24-26}$ A study by Kerr and McCarty ${ }^{24}$ compared patients with unipolar and bipolar lesions after arthroscopic debridement proving patients with unipolar lesions had higher outcome scores than those with bipolar lesions. Similarly, we detected slightly better Constant Score and Oxford Shoulder Score for isolated humeral compared with bipolar lesions. However, both of the patients requiring revision surgery had isolated ( 1 humeral and 1 glenoidal) and not bipolar lesions. Another recent study by Hünnebeck et l. $^{25}$ is widely in accordance with our data, describing very satisfying clinical long-term outcome following glenohumeral microfracturing. However, they also reported less favorable outcome when lesions were bipolar. Yet, the significance of such findings is not clear, as analyses of subgroups of patients with bipolar lesions is based on very small sample sizes in all available studies.

According to our findings, even appropriate imaging, a thorough patient history, and physical examination, symptomatic chondral lesions remain difficult to diagnose before arthroscopy. Literature confirms our experience regarding imaging studies being of limited value for the detection of chondral defects from the relatively thin cartilage in the shoulder. ${ }^{8,13}$ Because chondral lesions are often incidental intraoperative findings during shoulder arthroscopy rather than a pathology detected before surgery, it is often difficult to determine, if the chondral lesion is the primary problem leading to symptoms or just a secondary finding of limited clinical relevance.

One must bear in mind that the clinical outcome may not only be the effect of microfracturing, but also the result of procedures performed for concomitant pathologies. The treatment of such pathologies can undoubtedly have a positive effect on the overall outcome as well. Nevertheless, performance of microfracturing resulted in clinical improvement when localized cartilage defects were found at the glenohumeral articulating surfaces, independent of the presence of other pathologies. Similar results have been reported by Siebold et al. ${ }^{27}$ in 2003, Millet et al. ${ }^{7}$ in 2009, and Frank et al. ${ }^{13}$ in 2010 . Because its cost efficiency and easy accessibility remains a viable surgical option for patients with articular cartilage injuries measuring less than $2.5-\mathrm{cm}$ diameter, who wish to return to full activity, maximize function and alleviate pain at the same time.

Further research is necessary, not only to improve study design, but also to focus on the improvement of preoperative identification of chondral lesions and implementation of clinical algorithms to better identify patients, who could benefit most from a microfracturing procedure of the glenohumeral joint.

\section{Limitations}

This study has several limitations. First, the study is subject to all disadvantages of its retrospective design,

Table 3. Radiological Evaluation of Potential Progressive Glenohumeral Degeneration over the Study Period According to 4 Different Radiographic Grading Systems $(n=12)$

\begin{tabular}{|c|c|c|c|c|}
\hline & No Change & $\mathrm{I}^{\circ}$ Change & $\mathrm{II}^{\circ}$ Change & $\mathrm{III}^{\circ}$ Change \\
\hline \multirow[t]{3}{*}{ Kellgren and Lawrence $^{13}$} & $0^{\circ} \rightarrow 0^{\circ}, \mathrm{n}=7$ & $0^{\circ} \rightarrow 1^{\circ}, \mathrm{n}=2$ & & \\
\hline & $\underline{1^{\circ} \rightarrow 1^{\circ}, n=1}$ & $\underline{2^{\circ} \rightarrow 3^{\circ}, \mathrm{n}=1}$ & & $1^{\circ} \rightarrow 4^{\circ}, \mathrm{n}=1$ \\
\hline & Total, $n=8$ & Total, $n=3$ & Total, $\mathbf{n}=\mathbf{0}$ & Total, $\mathbf{n}=1$ \\
\hline \multirow{2}{*}{ Guyette et al. ${ }^{10}$} & $1^{\circ} \rightarrow 1^{\circ}, \mathrm{n}=1$ & $1^{\circ} \rightarrow 2^{\circ}, \mathrm{n}=1$ & $0^{\circ} \rightarrow 2^{\circ}, \mathrm{n}=1$ & $1^{\circ} \rightarrow 4^{\circ}, \mathrm{n}=1$ \\
\hline & Total, $n=8$ & Total, $n=2$ & Total, $\mathbf{n}=1$ & Total, $\mathbf{n}=1$ \\
\hline \multirow[t]{2}{*}{ Weinstein et al. ${ }^{28}$} & $\begin{array}{c}0^{\circ} \rightarrow 0^{\circ}, \mathrm{n}=7 \\
1^{\circ} \rightarrow 1^{\circ}, \mathrm{n}=1\end{array}$ & & & \\
\hline & Total, $\mathrm{n}=9$ & Total, $\mathbf{n}=\mathbf{2}$ & Total, $\mathbf{n}=1$ & Total, $\mathbf{n}=\mathbf{0}$ \\
\hline \multirow[t]{2}{*}{ Samilson and Pietro ${ }^{22}$} & $0^{\circ} \rightarrow 0^{\circ}, \mathrm{n}=8$ & $1^{\circ} \rightarrow 2^{\circ}, \mathrm{n}=2$ & $0^{\circ} \rightarrow 2^{\circ}, \mathrm{n}=1$ & $1^{\circ} \rightarrow 4^{\circ}, \mathrm{n}=1$ \\
\hline & Total, $n=8$ & Total, $n=2$ & Total, $\mathrm{n}=1$ & Total, $\mathrm{n}=1$ \\
\hline
\end{tabular}

NOTE. Degree sign represents radiographic level (or degree) of degeneration (I, II, or III degrees) according to the grading systems. $\mathrm{n}$ represents number of patients. "X RIGHT ARROW Y" represents the initial (X) and final (Y) degree of degeneration by number of patients (n) for each scale. 
relatively small number of patients, and the lack of a control group. Only baseline MRI scans were available; therefore, although progression of significant osteoarthritis could be monitored, subtle details such as chondral regeneration or fibrocartilage fill could not be verified. Microfracturing was not always performed as an isolated procedure, which limited the evaluation of its clinical value as a standalone procedure.

\section{Conclusion}

Glenohumeral microfracturing is commonly performed together with other procedures, but seems to be a feasible treatment option for contained cartilage lesions in active patients reproducibly yielding good mid- to long-term outcome.

\section{References}

1. Elser F, Braun S, Dewing CB, Millett PJ. Glenohumeral joint preservation: Current options for managing articular cartilage lesions in young, active patients. Arthroscopy 2010;26:685-696. doi:10.1016/j.arthro.2009.10.017.

2. Gross CE, Chalmers PN, Chahal J, et al. Operative treatment of chondral defects in the glenohumeral joint. Arthroscopy 2012;28:1889-1901. doi:10.1016/j.arthro. 2012.03.026.

3. Ruckstuhl H, de Bruin ED, Stussi E, Vanwanseele B. Posttraumatic glenohumeral cartilage lesions: A systematic review. BMC Musculoskelet Disord 2008;9:107. doi:10.1186/ 1471-2474-9-107.

4. Mundi R, Bedi A, Chow L, et al. Cartilage restoration of the knee. Am J Sports Med 2016;44:1888-1895. doi:10. $1177 / 0363546515589167$.

5. Schrock JB, Kraeutler MJ, Houck DA, McQueen MB, McCarty EC. A cost-effectiveness analysis of surgical treatment modalities for chondral lesions of the knee: Microfracture, osteochondral autograft transplantation, and autologous chondrocyte implantation. Orthop J Sport Med 2017;5:232596711770463. doi:10.1177/ 2325967117704634.

6. Saltzman BM, Leroux T, Cole BJ. Management and surgical options for articular defects in the shoulder. Clin Sports Med 2017;36:549-572. doi:10.1016/j.csm.2017.02.009.

7. Millett PJ, Huffard BH, Horan MP, Hawkins RJ, Steadman JR. Outcomes of full-thickness articular cartilage injuries of the shoulder treated with microfracture. Arthroscopy 2009;25:856-863. doi:10.1016/j.arthro.2009.02.009.

8. Cole BJ, Yanke A, Provencher MT. Nonarthroplasty alternatives for the treatment of glenohumeral arthritis. $J$ Shoulder Elb Surg 2007;16:S231-S240 (5 Suppl). doi:10.1016/j.jse.2007.03.011.

9. Carroll KW, Helms CA, Speer KP. Focal articular cartilage lesions of the superior humeral head: MR imaging findings in seven patients. Am J Roentgenol 2001;176:393-397. doi:10.2214/ajr.176.2.1760393.

10. Krishnan SG, Nowinski RJ, Harrison D, Burkhead WZ. Humeral hemiarthroplasty with biologic resurfacing of the glenoid for glenohumeral arthritis. Two to fifteen-year outcomes. J Bone Joint Surg Am 2007;89:727-734. doi:10. $2106 / J B J S . E .01291$.

11. Steadman JR, Rodkey WG, Rodrigo JJ. Microfracture: Surgical technique and rehabilitation to treat chondral defects. Clin Orthop Relat Res 2001;S362-S369 (391 Suppl). http:// www.ncbi.nlm.nih.gov/pubmed/11603719.

12. Gill TJ, Asnis PD, Berkson EM. The treatment of articular cartilage defects using the microfracture technique. J Orthop Sports Phys Ther 2006;36:728-738. doi:10.2519/ jospt.2006.2444.

13. Frank RM, Van Thiel GS, Slabaugh MA, Romeo AA, Cole BJ, Verma NN. Clinical outcomes after microfracture of the glenohumeral joint. Am J Sports Med 2010;38: 772-781. doi:10.1177/0363546509350304.

14. Yeh LR, Kwak S, Kim YS, et al. Evaluation of articular cartilage thickness of the humeral head and the glenoid fossa by MR arthrography: Anatomic correlation in cadavers. Skeletal Radiol 1998;27:500-504. http://www.ncbi. nlm.nih.gov/pubmed/9809879.

15. Outerbridge RE. The etiology of chondromalacia patellae. J Bone Joint Surg Br 1961;43-B:752-757. http://WwW.ncbi. nlm.nih.gov/pubmed/14038135.

16. Hensley CP, Sum J. Physical therapy intervention for a former power lifter after arthroscopic microfracture procedure for grade IVglenohumeral chondral defects. Int $J$ Sports Phys Ther 2011;6:10-26. http://www.ncbi.nlm.nih. gov/pubmed/21655454.

17. Buckwalter JA. Articular cartilage injuries. Clin Orthop Relat Res 2002:21-37. http://www.ncbi.nlm.nih.gov/ pubmed/12218470.

18. Buckwalter JA. Articular cartilage: injuries and potential for healing. J Orthop Sports Phys Ther 1998;28:192-202. doi:10.2519/jospt.1998.28.4.192.

19. Lewis PB, McCarty LP, Kang RW, Cole BJ. Basic science and treatment options for articular cartilage injuries. J Orthop Sports Phys Ther 2006;36:717-727. doi:10.2519/ jospt.2006.2175.

20. Guyette TM, Bae H, Warren RF, Craig E, Wickiewicz TL. Results of arthroscopic subacromial decompression in patients with subacromial impingement and glenohumeral degenerative joint disease. J shoulder Elb Surg 2002;11:299-304. doi:10.1067/mse. 2002.124427.

21. Weinstein DM, Bucchieri JS, Pollock RG, Flatow EL, Bigliani LU. Arthroscopic debridement of the shoulder for osteoarthritis. Arthrosc J Arthrosc Relat Surg 2000;16: 471-476. doi:10.1053/jars.2000.5042.

22. Kellgren JH, Lawrence JS. Radiological assessment of osteo-arthrosis. Ann Rheum Dis 1957;16:494-502., http:// www.ncbi.nlm.nih.gov/pubmed/13498604.

23. Samilson RL, Prieto V. Dislocation arthropathy of the shoulder. J Bone Jt Surg 1983;65:456-460. http://Www. ncbi.nlm.nih.gov/pubmed/6833319.

24. Kerr BJ, McCarty EC. Outcome of arthroscopic débridement is worse for patients with glenohumeral arthritis of both sides of the joint. Clin Orthop Relat Res 2008;466: 634-638. doi:10.1007/s1 1999-007-0088-0.

25. Hünnebeck SM, Magosch P, Habermeyer P, Loew M, Lichtenberg S. Chondral defects of the glenohumeral 
joint. Obere Extrem 2017;12:165-170. doi:10.1007/s1 1678017-0415-3.

26. Snow M, Funk L. Microfracture of chondral lesions of the glenohumeral joint. Int J Shoulder Surg 2008;2:72. doi:10. 4103/0973-6042.44142.
27. Siebold R, Lichtenberg S, Habermeyer P. Combination of microfracture and periostal-flap for the treatment of focal full thickness articular cartilage lesions of the shoulder: a prospective study. Knee Surg Sports Traumatol Arthrosc 2003;11:183-189. doi:10.1007/s00167-003-0363-x. 